\title{
Isolamento, fracionamento e avaliação toxicológica in vivo de polissacarídeos sulfatados de Hypnea musciformis
}

\author{
Isolation, fractionation and in vivo toxicological evaluation of sulfated polysaccharides \\ from Hypnea musciformis
}

\author{
José Ariévilo Gurgel Rodrigues ${ }^{\mathbb{I}}$ Ianna Wivianne Fernandes de Araújo ${ }^{I}$ Gabriela Almeida de Paula \\ Edfranck de Sousa Oliveira Vanderlei" Ismael Nilo Lino de Queiroz ${ }^{\mathrm{II}}$ Ana Luíza Gomes Quinderé ${ }^{\mathrm{II}}$ \\ Chistiane Oliveira Coura ${ }^{\text {II }}$ Érika Façanha Bessa ${ }^{\text {III }}$ Ticiana de Brito Lima ${ }^{\text {II }}$ \\ Norma Maria Barros Benevides ${ }^{\mathrm{II} *}$
}

RESUMO

\begin{abstract}
Objetivou-se isolar, fracionar e avaliar a toxicidade in vivo dos polissacarídeos sulfatados (PSs) da rodofícea Hypnea musciformis, quando obtidos por três métodos de extração (M I; M II e M III). Os PSs foram extraídos com papaína em tampão acetato de sódio $100 \mathrm{mM}(\mathrm{pH} 5,0)$, contendo cisteína e EDTA $(5 \mathrm{mM})$ (M I) ou água $\left(25-80^{\circ} \mathrm{C}(\mathrm{M} \mathrm{II}) ; 80^{\circ} \mathrm{C}\right.$ (M III)) e, em seguida, determinados sua composição química de carboidratos totais, sulfato livre $(S L)$ e proteínas contaminantes (PCs). Os PSs foram submetidos à cromatografia de troca iônica (DEAE-celulose) usando um gradiente de cloreto de sódio, sendo avaliado o grau de homogeneidade e densidade de carga por eletroforese em gel de agarose das frações obtidas e comparadas à heparina. $O$ ensaio in vivo foi realizado em grupos $(n=6)$ de camundongos Swiss machos e fêmeas (24-33g), os quais receberam: PSs (9mg $\mathrm{kg}^{-1}$; i.p.) isentos do PCs (M I) e salina 0,9\% $\left(0,1 \mathrm{~mL} 10 \mathrm{~g}^{-1}\right.$; i.p.), durante 14 dias consecutivos. No 15o dia, os animais foram anestesiados e sacrificados para coletas de sangue $e$ órgãos, os quais foram utilizados para dosagens bioquímicas e correlações com suas massas corpóreas, respectivamente. $O$ teor de $S L(31,05 \pm 0,53 \%)(P<0,05)$ e o fracionamento, em DEAE-celulose, indicaram o M I mais eficiente na obtenção de PSs, comparado ao M II e M III. Os animais mostraram-se tolerantes aos PSs do M I e não se observou alteração de ordem hepática ou renal $(P>0,05)$.
\end{abstract}

Palavras-chave: rodofícea, polímeros sulfatados, métodos de extração, avaliação sistêmica.

\section{ABSTRACT}

This study aimed to isolate, fractionate and evaluate the in vivo toxicity of sulfated polysaccharides (SPS) from Hypnea musciformis (Rhodophyta), when obtained by three extraction methods (M I, M II and M III). SPs were extracted with papain in $100 \mathrm{mM}$ sodium acetate ( $\mathrm{pH}$ 5.0) containing cysteine and EDTA $(5 \mathrm{mM})(\mathrm{M} \mathrm{I})$ or water $\left(25-80^{\circ} \mathrm{C}\right.$ (M II $\left.), 80^{\circ} \mathrm{C}(\mathrm{M} \mathrm{III})\right)$, and then their chemical composition of total carbohydrates, free sulfate (FS) and contaminant proteins $(C P S)$ was determined. SPs were submitted to ion-exchange chromatography (DEAE-celulose) using a sodium chloride gradient, being the degree of homogeneity and charge density evaluated by agarose gel electrophoresis of the fractions obtained and compared to heparin. The in vivo assay was performed using groups $(n=6)$ of male and female Swiss mice (24-33g), which received: SPs (9mg $\mathrm{kg}^{-1}$, i.p.) absence of CPS (M I) and $0.9 \%$ saline (0.1mL $10 \mathrm{~g}^{-1}$, i.p.), for 14 consecutive days. On the $15^{\text {th }}$ day, collect blood and organs for biochemical dosages and corporal mass correlation, respectively, from the animals anesthetized and sacrificed were performed. The sulfate content of FS $(31.05 \pm 0.53 \%)(P<0.05)$ and the fractionation by DEAE-cellulose showed M I more effectiveness in obtaining SPs compared to M II and M III. The animals were tolerable to SPs from M I, and it wasn't observed hepatic or renal alteration $(P>0.05)$

Key words: rhodophyta, sulfated polymers, extraction methods, systemic evaluation.

\section{INTRODUÇÃO}

As macroalgas marinhas biossintetizam polissacarídeos sulfatados (PSs) de grande interesse em Biotecnologia, como, por exemplo, nas ciências de alimentos (CAMPO et al., 2009) e médicas (PEREIRA et

'Programa de Pós-graduação em Biotecnologia, Rede Nordeste de Biotecnologia (RENORBIO), Fortaleza, CE, Brasil.

"Programa de Pós-graduação em Bioquímica, Universidade Federal do Ceará (UFC), Fortaleza, CE, Brasil.

IIIDepartamento de Bioquímica e Biologia Molecular, UFC, Av. Mister Hull, s/n, 60451-970, Fortaleza, CE, Brasil. E-mail: nmbb@ufc.br. *Autor para correspondência. 
al., 2005; FONSECA et al., 2008; RODRIGUES et al., 2011a). As diversas propriedades desses compostos têm motivado a maricultura de algas no Brasil, como, por exemplo, as espécies rodofíceas Hypnea musciformis (REIS et al., 2006) e Solieria filiformis (RODRIGUES et al., 2010), além de propiciar estudos relacionados à biologia de algas, extração e caracterização físico-química e de atividades biológicas de ficocolóides (RODRIGUES et al., 2010; RODRIGUES et al., 2011b).

As carragenanas representam uma família de PSs que sofrem diversas variações originadas de substituições das hidroxilas livres. Esses polímeros são formados por unidades dissacarídicas repetitivas de cadeias alternadas de unidades $1 \rightarrow 3$ ligada à $\beta$-Dgalactopiranose e $1 \rightarrow 4$ ligada à a-D-galactopiranose, sendo divididos em seis formas básicas, a saber: Iota

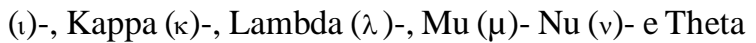
( $\theta$ )-carragenanas, cujas três primeiras, que diferem entre si pelo número, localização do radical sulfato na estrutura química e pela presença da ligação 3,6 anidrogalactose, são consideradas os principais copolímeros de interesse comercial. Tal classificação diferencia as fontes de espécies rodofíceas produtoras, sendo as carragenanas comerciais extraídas principalmente de algas marinhas dos gêneros Gigartina, Chondrus, Eucheuma e Hypnea (CAMPO et al., 2009; SILVA et al., 2010).

Pesquisas revelam que o emprego de diferentes metodologias na extração de PSs pode ocasionar variação no rendimento, características físico-químicas e atividade biológica (CAMPO et al., 2009). ECCLES et al. (2010) demonstraram que uma 1carragenana, na forma de spray, faz-se segura e eficaz no tratamento de pessoas acometidas de sintomas respiratórios, podendo ser utilizada como descongestionante nasal e antisecretório. carragenanas extraídas com papaína da alga marinha vermelha $\boldsymbol{S}$. filiformis apresentam atividade anticoagulante in vitro, comparadas àquelas destituídas de atividades obtidas da extração com água (RODRIGUES et al., 2010). SILVA et al. (2010) relataram que carragenanas comerciais $(1-, \kappa-\mathrm{e} \lambda-)$ apresentam atividades anticoagulante in vitro e edematogênica in vivo. Segundo a revisão de CAMPO et al. (2009), o uso de carragenanas degradadas como aditivos alimentares, quando testadas em modelos animais, induziram ulcerações intestinais e efeitos colaterais, sugerindo maiores os estudos sobre a utilização de PSs na dieta. Assim, estudos toxicológicos in vivo sobre PSs também contribuem para esse fim (LI et al., 2005; ASSREUY et al., 2008; LINS et al., 2009; SIQUEIRA et al., 2011).

A alga marinha vermelha $\boldsymbol{H}$. musciformis (Wulfen) J. V. Lamouroux possui a $k$-carragenana como principal PS de parede celular. Esse ficocolóide apresenta propriedades funcionais físicas de interesse para a indústria de alimentos (CAMPO et al., 2009) e com capacidade de alterar a coagulação sanguínea in vitro (RODRIGUES et al., 2011b). O objetivo desta pesquisa foi isolar e fracionar os PSs de $\boldsymbol{H}$. musciformis, quando obtidos por três métodos de extração (papaína e água), assim como avaliar a toxicidade in vivo em camundongos, contribuindo com os estudos relacionados à identificação e caracterização química desses polímeros presentes na espécie e para obtenção de novas moléculas com mínimos efeitos.

\section{MATERIAL E MÉTODOS}

Tratamento da alga marinha, extração e análises da composição química dos PSs

Exemplares de $\boldsymbol{H}$. musciformis foram obtidos do cultivo experimental da alga $\boldsymbol{S}$. filiformis em estruturas conhecidas como "long-line", durante procedimentos de amostragens dessa espécie, localizadas a $200 \mathrm{~m}$ da zona costeira da Praia de Flecheiras, município de Trairí-Ceará $\left(039^{\circ} 16^{\prime} 47^{\prime}\right.$ ' W e $03^{\circ} 13^{\prime} 06^{\prime}$ 'S). No laboratório de Carboidratos e Lectinas (CarboLec) do Departamento de Bioquímica e Biologia Molecular, Universidade Federal do Ceará, as algas foram tratadas e acondicionadas como relatadas previamente (RODRIGUES et al., 2011). Para a extração dos PSs, três protocolos foram utilizados a partir do tecido da alga $(5 \mathrm{~g})$ desidratado $\left(25^{\circ} \mathrm{C}\right)$ e macerado em nitrogênio líquido.

Extração por digestão enzimática (Método I) Os PSs foram extraídos com papaína bruta $\left(30 \mathrm{mg} \mathrm{mL}^{-1}\right)$ em tampão acetato de sódio $100 \mathrm{mM}$ (pH 5,0) contendo cisteína eEDTA $(5 \mathrm{mM})$ em banho-maria $\left(6 \mathrm{~h} ; 60^{\circ} \mathrm{C}\right)$ como descrito previamente (RODRIGUES et al., 2011b).

Extração aquosa total (Método II) - Para extração dos PSs, o tecido da alga foi hidratado em água destilada $\left(1,5 \%\right.$; massa volume $\left.{ }^{-1}\right)$ e inicialmente submetido à agitação constante $\left(25^{\circ} \mathrm{C}\right)$ em placa por 24h. Em seguida, o material foi centrifugado (2295 $\times$ g; $10^{\circ} \mathrm{C}$; 30min) e, ao sobrenadante, adicionado etanol comercial (1:3; $\left.\mathrm{v} \mathrm{v}^{-1}\right)$ para precipitação dos PSs (24h; $4^{\circ} \mathrm{C}$ ). Posteriormente, o tecido foi re-extraído em banhomaria $\left(4 \mathrm{~h} ; 80^{\circ} \mathrm{C}\right)$, sendo os PSs precipitados com adição de etanol comercial $\left(1: 3 ; \mathrm{v} \mathrm{v}^{-1}\right)$ por $24 \mathrm{~h} \mathrm{a} 4^{\circ} \mathrm{C}$. Logo após a precipitação, os PSs foram centrifugados. O rendimento de PSs foi calculado somando-se ambas as extrações (fria e quente).

Extração aquosa refinada (Método III) Inicialmente, o tecido da alga foi hidratado em água destilada $\left(1,5 \%\right.$; massa volume $\left.{ }^{-1}\right)$ e submetido à agitação constante $\left(25^{\circ} \mathrm{C}\right) \mathrm{em}$ placa por $24 \mathrm{~h}$. O material 
obtido foi descartado. Após re-extração do tecido em banho-maria $\left(4 \mathrm{~h} ; 80^{\circ} \mathrm{C}\right)$, os PSs foram precipitados $(24 \mathrm{~h}$ a $\left.4^{\circ} \mathrm{C}\right)$ com adição de etanol comercial $\left(1: 3 ; \mathrm{v} \mathrm{v}^{-1}\right)$ e, em seguida, centrifugados $\left(2295 \times \mathrm{g} ; 10^{\circ} \mathrm{C} ; 30 \mathrm{~min}\right)$.

A qualidade dos PSs foi avaliada quanto sua composição química de carboidratos totais (CTs), determinados pelo método de placa em leitor de ELISA utilizando a D-galactose como padrão (MASUKO et al., 2005), de sulfato livre (SL), utilizando uma curvapadrão de sulfato de sódio (DODGSON \& PRICE, 1962) e de proteínas contaminantes (PCs), usando a albumina sérica bovina como padrão (BRADFORD, 1976). Os dados de rendimento e composição química dos PSs liofilizados foram analisados por variância (ANOVA) e, quando foi observada diferença entre os métodos empregados, utilizou-se o teste de Tukey, considerando $\mathrm{P}<0,05$.

Cromatografia de troca iônica (DEAE-celulose) e eletroforese em gel de agarose

Os PSs (50mg) foram dissolvidos em tampão acetato de sódio $0,05 \mathrm{M}\left(2 \mathrm{mg} \mathrm{mL}^{-1}\right)$ e submetidos à cromatografia de troca iônica em coluna de DEAEcelulose $(24,5 \times 1 \mathrm{~cm})$ (Sigma-Aldrich, St. Louis, EUA). As frações $(5,6 \mathrm{~mL})$ eluídas com 0,50 e $0,75 \mathrm{M}$ de cloreto de sódio foram dialisadas exaustivamente contra água destilada e liofilizadas. As frações de PSs eluídas com $0,50 \mathrm{M}$ de sal foram analisadas quanto ao grau de homogeneidade e densidade de carga por eletroforese em gel de agarose (BioAgency, São Paulo, SP, Brasil) a 0,5\% em tampão 1,3-acetato diaminopropano (0,05M) (Sigma-Aldrich, St. Louis, EUA) (pH9,0) e comparadas à heparina. Ambos os procedimentos foram realizados como relatados anteriormente (RODRIGUES et al., 2011b).

Avaliação dos efeitos sistêmicos em camundongos Camundongos Swiss machos e fêmeas (24$33 \mathrm{~g}$ ) foram cedidos pelo Biotério Central da Universidade Federal do Ceará e mantidos com fotoperíodo de 12 horas (claro/escuro), temperatura controlada, recebendo água e alimentação ad libitum. Todos os cuidados foram realizados de forma a reduzir o estresse dos animais na execução deste experimento. O presente trabalho recebeu aprovação da Comissão de Ética em Pesquisa Animal - CEPA, com protocolo para uso de animais em experimentação n. 125/07.

$\mathrm{O}$ ensaio in vivo foi realizado em grupos $(\mathrm{n}=6)$ de camundongos, os quais receberam: PSs $(9 \mathrm{mg}$

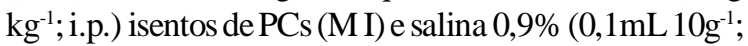
i.p.), durante 14 dias consecutivos. Durante o experimento, os animais foram observados considerando os seguintes aspectos: variação de massa corporal, taxa de sobrevida, alterações de mucosas, olhos, ereção de pêlos, apatia e/agressividade, entre outros. No 15을 dia, os animais foram anestesiados com hidrato cloral a $10 \%$ (i.p.) e amostras de sangue (plexo orbital) adicionadas de citrato de cálcio $(3,2 \%)$ foram coletadas e centrifugadas $\left(1000 \times g ; 25^{\circ} \mathrm{C} ; 3 \mathrm{~min}\right)$ para posteriores dosagens séricas de uréia e de alanina e aspartato transferases (ALT e AST), segundo especificações do fabricante $\left(\right.$ Labtest $\left.^{\circledR}\right)$. Depois de sacrificados, procedeu-se à remoção e à pesagem de órgãos (coração, fígado e rim) dos animais, mantendo correlações com as respectivas massas corpóreas. Os resultados foram expressos como média \pm erro-padrão. Para a verificação das diferenças entre os grupos, aplicou-se o teste de $t$-Student, considerando $\mathrm{P}<0,05$ (SIQUEIRA et al., 2011).

\section{RESULTADOS E DISCUSSÃO}

O rendimento de PSs liofilizados de $\boldsymbol{H}$. musciformis diferiu entre os métodos utilizados. Baseada na alga desidratada $\left(25^{\circ} \mathrm{C}\right)$ e macerada (massa/ massa \%), o emprego do M I resultou em 20,80 $\pm 0,36 \%$ de PSs quando comparado ao M II e M III $(36,80 \pm 1,27$ e $24,20 \pm 0,87 \%$, respectivamente) $(\mathrm{P}<0,05)$. PEREIRA et al. (2005) obtiveram 2,60\% do rendimento de PSs extraídos com papaína da rodofícea Gelidium crinale. AZIZA et al. (2008) avaliaram o efeito da variação sazonal sobre o rendimento de PSs extraídos em meio aquoso $\left(90^{\circ} \mathrm{C}\right.$; 5h) de $\boldsymbol{H}$. musciformis coletada em Marrocos e obtiveram 34,50-41,00\%. Extrações consecutivas de PSs (M I) da Rhodophyta Halymenia pseudofloresia resultaram em 47,14\% (RODRIGUES et al., 2009). Segundo RODRIGUES et al. (2011b), utilizando a $\boldsymbol{H}$. musciformis oriunda do cultivo de $\boldsymbol{S}$. filiformis em Flecheiras, Trairí-CE, os autores obtiveram 49,05 e 44,77\% de PSs (M I e M II, respectivamente), após secos em estufa $\left(60^{\circ} \mathrm{C} ; 3 \mathrm{~h}\right)$.

$\mathrm{Na}$ análise da composição química, observou-se que o método de extração utilizado influenciou sobre a qualidade dos PSs obtidos. O maior teor de SL foi encontrado para o M I $(31,05 \pm 0,53 \%)$ $(\mathrm{P}<0,05)$ em relação ao M II e M III $(24,20 \pm 0,21$ e $20,17 \pm 1,87 \%$, respectivamente). No geral, tais teores foram semelhantes quando comparados aqueles obtidos de PSs extraídos em meio aquoso $\left(90^{\circ} \mathrm{C} ; 5 \mathrm{~h}\right) \mathrm{de}$ H. musciformis por AZIZA et al. (2008) e de PSs comerciais dos tipos $\kappa-,, \imath-\mathrm{e} \lambda$-carragenanas (SILVA et al., 2010). Os teores de CTs foram 55,81 $\pm 0,37 ; 66,21 \pm 0,23$ e 61,32 $\pm 0,43 \%$, respectivamente, para M I; M II e M III $(\mathrm{P}<0,05)$, sendo também semelhantes aos obtidos de carragenanas comerciais por SILVA et al. (2010). Os PSs obtidos pelo M I mostraram-se isentos de PCs, 
enquanto dos extraídos em água apresentaram teores de $1,51 \pm 0,19$ e $0,57 \pm 0,33 \%$ para M II e M III, respectivamente $(\mathrm{P}<0,05)$.

Avaliando o resultado da extração com papaína de PSs do tipo tcarragenanas da alga marinha vermelha cultivada $\boldsymbol{S}$. filiformis, RODRIGUES et al. (2010) obtiveram teores de SLe CTs (29,40 e 42,00\%, respectivamente) superiores daqueles extraídos em água (24,80 e 32,00\% para SLe CTs, respectivamente). Os PSs da extração com papaína também foram isentos de PCs. Para CAMPO et al. (2009), a qualidade do ficocoloide extraído agrega maior valor ao produto no mercado internacional para uso nas indústrias alimentícia e farmacêutica.

Neste trabalho, diferenças foram encontradas na composição química dos PSs entre os métodos utilizados. O maior rendimento de PSs foi obtido pelo M II, o que pode ser o resultado da extração de precursores (galactose-6-sulfato) e outros elementos constituintes não formadores de gel, comuns em algas marinhas vermelhas e presentes nas camadas mais externas do tecido, haja vista a extração aquosa a frio, que foi realizada previamente sob agitação constante, possuir a propriedade de remover tais componentes, enquanto a extração aquosa a quente obter polissacarídeos conhecidos como "amido das florídeas", os quais são ricos em glucose (MURANO et al., 1997), além de justificar os maiores teores de CTs e PCs encontrados no referido método, comparado aos demais. Assim, para comprovar a presença de constituintes químicos em $\boldsymbol{H}$. musciformis, estudos estruturais seriam indicados (MURANO et al., 1997; CAMPO et al., 2009; SILVA et al., 2010).

Os perfis cromatográficos dos PSs, em DEAE-celulose, mostraram a separação de duas diferentes frações de PSs (FI e F II) realizadas com 0,50 e $0,75 \mathrm{M}$ de $\mathrm{NaCl}$, respectivamente. As maiores metacromasias foram verificadas para as frações $\mathrm{F} \mathrm{I} \mathrm{e} \mathrm{F}$ II (M I), cujos rendimentos de PSs, calculados a partir da quantidade de material bruto aplicado no gel de DEAE-celulose (PEREIRA et al., 2005), foram 8,80 e $3,00 \%$, respectivamente, além de justificar o maior teor de SL obtido. As frações F I e F II (M II e M III), cujos métodos apresentaram menores teores de SL, resultaram em rendimentos de 6,80 e $2,80 \%$ e de 4,60 e $2,50 \%$, respectivamente. A menor detecção de CTs no M II e M III (Figuras 1B e C) possivelmente foi ocasionada pela extração de carboidratos neutros que não interagem com o gel de DEAE-celulose, tendo em vista o perfil de CTs apresentado pelo M I (Figura 1A).

A análise do perfil eletroforético revelou mobilidade de corrida semelhante entre frações de PSs (F I) e heparina. No geral, bandas com baixo grau de polidispersão foram ainda verificadas entre os PSs avaliados (Figura 1D). Segundo RODRIGUES et al. (2009), digestões consecutivas com papaína da alga marinha vermelha $\boldsymbol{H}$. pseudofloresia resulta em moléculas heterogêneas na primeira extração, enquanto na segunda e terceira extrações ocasionam a obtenção de PSs mais homogêneos.

A tabela 1 mostra o resultado da avaliação dos parâmetros corporais e as dosagens bioquímicas. Verificou-se que os camundongos, sistemicamente tratados $\left(9 \mathrm{mg} \mathrm{kg}^{-1}\right.$; i.p.) (dose selecionada a partir de um ensaio de contorções abdominais induzidas por ácido acético - dados não publicados) com os PSs de H. musciformis, que se apresentaram isentos de PCs (M I), foram tolerantes às aplicações durante os 14 dias consecutivos experimentais. Apesar da variação de massa corpórea apresentada pelos animais no decorrer do período de avaliação, não se constatou diferenças significantes entre os grupos PSs e salina. Além de os animais terem apresentado incremento de peso ao final do experimento, sugerindo que os PSs não afetaram a massa corpórea dos animais em relação ao grupo salina $(\mathrm{P}>0,05)$ (LINS et al., 2009; SIQUEIRA et al., 2011). Coração, fígado e rim também se apresentaram normais, exceto da diminuição observada para o coração do grupo das fêmeas $(\mathrm{P}<0,05)$, possivelmente indicando um menor estresse cardíaco.

Fucoidana extraída da alga marinha parda Laminaria japonica, para avaliação de seu efeito toxicológico em ratos, foi relatada por LI et al. (2005). Segundo os autores, administrações de 100; 500; 1000; 2000 e $4000 \mathrm{~m} \mathrm{~kg}^{-1}$ de fucoidana não resultaram em sinais de toxicidade durante os sete dias de tratamento agudo. No experimento subcrônico oral (300; 900 e $2500 \mathrm{mg} \mathrm{kg}^{-1}$ ), durante os seis meses de tratamento, foi evidenciado ganho de peso final pelos animais, como também para este trabalho (Tabela 1). Segundo a revisão de CAMPO et al. (2009), carragenanas ingeridas como aditivos em alimentos podem induzir ulcerações intestinais, tornando um perigo para pessoas acometidas de problemas gastrointestinais.

$\mathrm{Na}$ presente pesquisa, alguns parâmetros físicos e de comportamento também foram avaliados nos animais, tais como mucosas ou olhos, ereção de pelos e outros comportamentos gerais. Segundo as observações, os animais que receberam os PSs de $\boldsymbol{H}$. musciformis mostraram-se normais. Esses fatos são importantes, tendo em vista a viscosidade apresentada pelos ficocolóides de algas (CAMPO et al., 2009). Segundo HEO et al. (2005), a digestão enzimática de algas resulta em rendimentos maiores de compostos bioativos e que mostram atividade biológica aumentada quando comparados aos obtidos de 
Tabela 1 - Avaliação sistêmica dos camundongos após tratamento durante 14 dias com polissacarídeos sulfatados extraídos com papaína da alga marinha epífita Hypnea musciformis.

\begin{tabular}{|c|c|c|c|c|}
\hline \multirow{3}{*}{ Parâmetros } & \multicolumn{4}{|c|}{---Tratamento $\left(9 \mathrm{~m} \mathrm{~kg}^{-1}\right.$; i.p. $)$} \\
\hline & \multicolumn{2}{|c|}{ - } & \multicolumn{2}{|c|}{ - } \\
\hline & Salina & PSs & Salina & PSs \\
\hline Massa corpórea $(\mathrm{g})$ inicial & $22,83 \pm 0,47$ & $23,67 \pm 0,33$ & $24,00 \pm 0,85$ & $24,83 \pm 0,47$ \\
\hline Massa corpórea (g) final & $25,67 \pm 0,61$ & $26,83 \pm 0,70$ & $31,83 \pm 1,01$ & $32,00 \pm 0,36$ \\
\hline Fígado $(\mathrm{g})$ massa corpórea ${ }^{-1}$ & $4,83 \pm 0,12$ & $5,05 \pm 0,21$ & $5,46 \pm 0,14$ & $5,37 \pm 0,13$ \\
\hline Rim (g) massa corpórea ${ }^{-1}$ & $0,63 \pm 0,02$ & $0,66 \pm 0,03$ & $0,76 \pm 0,03$ & $0,81 \pm 0,04$ \\
\hline Coração $(\mathrm{g})$ massa corpórea ${ }^{-1}$ & $0,67 \pm 0,01$ & $0,50 \pm 0,01^{*}$ & $0,57 \pm 0,04$ & $0,50 \pm 0,02$ \\
\hline Uréia $\left(\mathrm{mg} \mathrm{dL}^{-1}\right)$ & $45,81 \pm 0,05$ & $39,86 \pm 3,71$ & $58,13 \pm 0,12$ & $51,93 \pm 2,97$ \\
\hline AST $\left(\mathrm{U} \mathrm{L}^{-1}\right)$ & $43,25 \pm 13,90$ & $80,21 \pm 14,14$ & $48,41 \pm 14,44$ & $57,29 \pm 4,42$ \\
\hline $\operatorname{ALT}\left(\mathrm{U} \mathrm{L}^{-1}\right)$ & $19,31 \pm 1,23$ & $26,07 \pm 3,47$ & $15,06 \pm 1,06$ & $26,09 \pm 5,36$ \\
\hline
\end{tabular}

Os dados são expressos como médiaterro-padrão e foram analisados por meio do teste de $t$-Student. Foi considerado $\mathrm{P}<0,05$ como significante. * Indica diferença significativa.
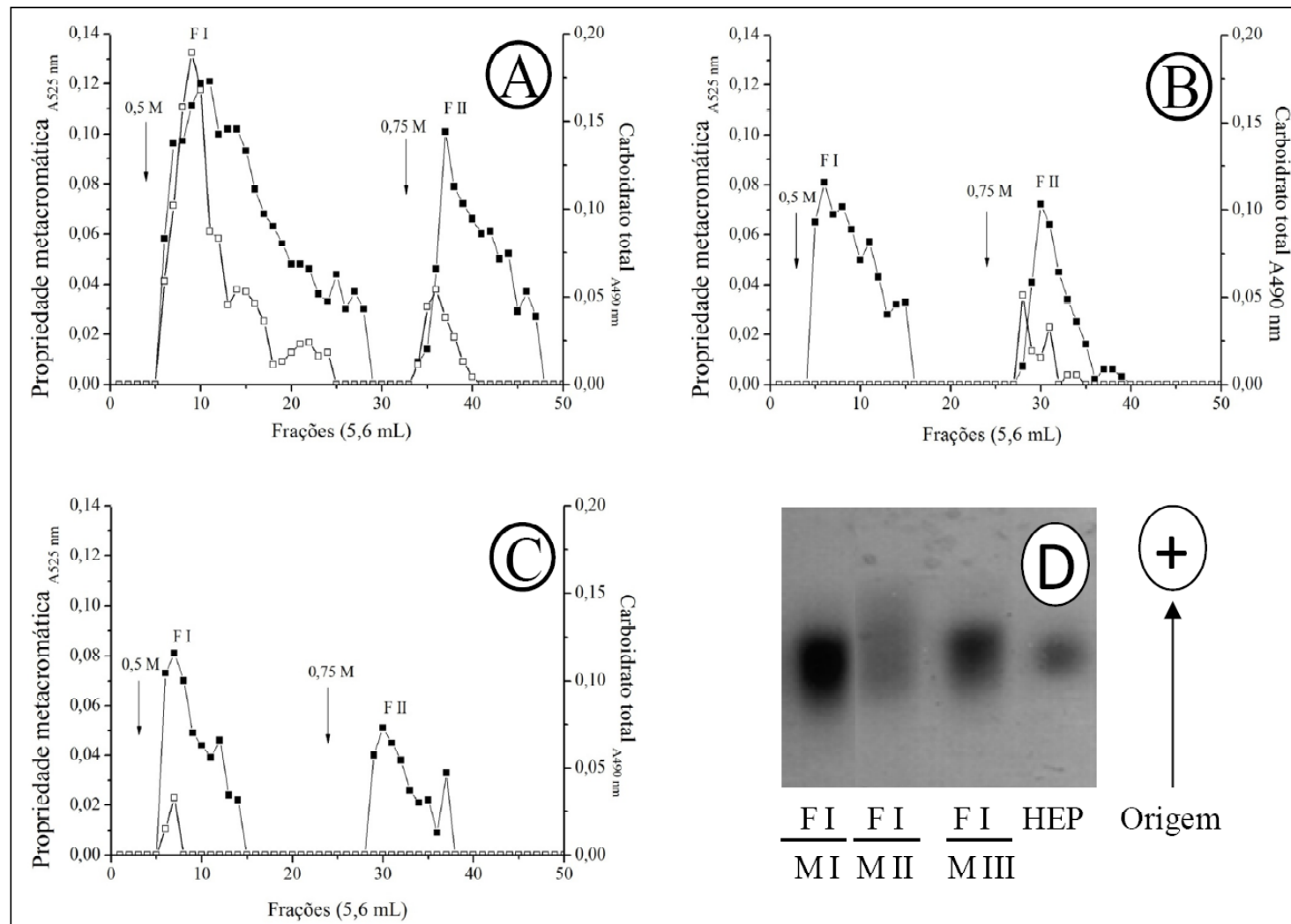

Figura 1 - Cromatografia de troca iônica (DEAE-celulose) dos polissacarídeos sulfatados (M I - A; M II - B e M III - C) da rodofícea Hypnea musciformis. A coluna foi equilibrada e eluída com tampão acetato de sódio a $0,05 \mathrm{M}(\mathrm{pH}$ $5,0)$ contendo cisteína e EDTA $(5 \mathrm{mM})$. Os polissacarídeos sulfatados adsorvidos no gel foram eluídos com adição $(\downarrow)$ de $\mathrm{NaCl}(0,50$ e $0,75 \mathrm{M})$. (-) metacromasia; (0) carboidratos totais. D, Eletroforese em gel de agarose a 0,5\% das frações F I comparadas à heparina (HEP). Os polissacarídeos presentes no gel foram corados com azul de toluidina a $0,1 \%$. 
extratos em água e orgânicos, uma vez que enzimas tornam materiais insolúveis para solúveis em água, além da obtenção de compostos químicos ausentes de toxicidade. Assim, as dosagens de uréia, ALT e AST, usadas como marcadores de funções renais ou hepáticas, também não diferiram a partir dos grupos controles. Isso sugere que os PSs de $\boldsymbol{H}$. musciformis não causaram dano hepatocelular ou renal (LI et al., 2005). RODRIGUES et al. (2011b) demonstraram que os PSs de $\boldsymbol{H}$. musciformis também mostraram-se capazes de alterar discretamente a coagulação sanguínea in vitro. Os dados obtidos na tabela 1 podem ser considerados valiosos desde que a heparina, um PS mundialmente utilizado como anticoagulante e antitrombótico, pode ocasionar alterações na atividade das aminotransferases no plasma (MAJERUS \& TOLLENSEN, 2005). Além disso, PSs capazes de modificar significativamente a coagulação normal podem comprometer o tratamento de pacientes acometidos de doenças renais (LI et al., 2005).

Avaliando os efeitos sistêmicos de uma galactana sulfatada da alga marinha vermelha Champia feldmannii, ASSREUY et al. (2008) observaram que camundongos tratados (30 $\mathrm{mg} \mathrm{kg}^{-1}$; i.v.) não exibiram, após $48 \mathrm{~h}$, nenhum sinal de toxicidade aguda. Segundo SIQUEIRA et al. (2011), o tratamento diário (1 $\mathrm{mg} \mathrm{kg}^{-1}$; i.v.) de ratos, durante sete dias consecutivos, com um PS isolado da alga marinha parda Lobophora variegata, não altera o equilíbrio osmótico, preserva o número de células de defesa e não produz alterações de ordem hepática ou renal. Estudos adicionais, com a finalidade de melhor averiguar os efeitos sistêmicos dos PSs de $\boldsymbol{H}$. musciformis, serão realizados por nosso grupo de pesquisa.

\section{CONCLUSÃO}

Os polissacarídeos sulfatados da rodofícea Hypnea musciformis mostram-se melhor extraídos com papaína, comparados dos extraídos com água. O tratamento subcrônico, no decorrer de 14 dias consecutivos, de camundongos com os polissacarídeos sulfatados provenientes da extração com papaína não resulta em efeitos sistêmicos importantes.

\section{AGRADECIMENTOS}

Ao Programa da Rede Nordeste de Biotecnologia (Renorbio), à Fundação Cearense de Apoio ao Desenvolvimento Científico e Tecnológico (Funcap), ao Conselho Nacional de Desenvolvimento Científico e Tecnológico (CNPq), à Coordenação de Aperfeiçoamento de Pessoal de Nível Superior (Capes), ao Ministério da Ciência e Tecnologia e Ministério da Saúde.

\section{REFERÊNCIAS}

ASSREUY, A.M.S. et al. Biological effects of a sulfated polysaccharide isolated from the marine red algae Champia feldmannii. Biological \& Pharmaceutical Bulletin, v.31, n.4, p.691-695, 2008. Disponível em: <http://www.jstage.jst.go.jp/ article/bpb/33/5/33_830/_article>. Acesso em: 17 maio, 2011. doi: $10.1248 / \mathrm{bpb} .33 .830$.

AZIZA, M. et al. Seasonal variation of the growth, chemical composition and carrageenan extracted from Hypnea musciformis (Wulfen) Lamouroux harvested along the Atlantic coast of Marocco. Scientific Research and Essay, v.2, n.10, p.509514, 2008. Disponível em: <http://www.academicjournals.org/ sre/PDF/pdf2008/Oct/Aziza\%20et\%20al\%20Pdf.pdf $>$. Acesso em: 17 maio, 2011.

BRADFORD, M.M. A rapid and sensitive method for the quantification of microgram quantities of protein utilizing the principle of protein-dye binding. Analytical Biochemistry, v.72, n.1-2, p.248-254, 1976.

CAMPO, V.L. et al. Carrageenans: biological properties, chemical modifications and structural analysis - a review. Carbohydrate Polymers, v.77, n.2, p.167-180, 2009. Disponível em: <http:/ / w w w. s c i e n c e d i r e c t . c o m / science?_ob=ArticleURL\&_udi=B 6TFD-4VH4DGB$2 \&$ _user $=10 \&$ _coverDate $=06 \% 2 \mathrm{~F} 10 \% 2 \mathrm{~F} 2009 \&$ \&alid $=175543$ $5480 \& \_r d o c=1 \&$ fmt $=$ high \&_orig $=$ search \&_origin $=$ search \&_ zone=rsit_list_item\&_cdi $=5224 \& \_s o r t=r \& \_s t=13 \& \_d o c a n c h o r=\& v i e w=$ c\&_ct $=205 \&$ \&acct $=$ C000050221\&_version $=1 \&$ \&urlVersion $=0 \&$ _userid $=10 \& \mathrm{md} 5=66266 \mathrm{~cd} 07701 \mathrm{a} 312 \mathrm{~b} 4 \mathrm{af} 50207 \mathrm{~d} 9 \mathrm{a} 3 \mathrm{c} 37 \&$ sea rchtype $=\mathrm{a}>$. Acesso em: 17 maio, 2011. doi: 10.1016/ j.carbpol.2009.01.020.

DODGSON, K.S.; PRICE, R.G. A note on the determination of the ester sulfate content of sulfated polysaccharides. Biochemistry Journal, v.84, n.1, p.106-110, 1962.

ECCLES, R. et al. Efficacy and safety of an antiviral iota carrageenan nasal spray: a randomized, double-blind, placebocontrolled exploratory study in volunteers with early symptoms of the common cold. Respiratory Research, v.11, n.108, p.2-10, 2010. Disponível em: <http://respiratory-research.com/ content/11/1/108>. Acesso em: 17 maio, 2011. doi: 10.1186/ 1465-9921-11-108

FONSECA, R.J.C. et al. Slight differences in sulfatation of algal galactans account for differences in their anticoagulant and venous antithrombotic activities. Thrombosis and Haemostasis, v.99, v.3, p.539-545, 2008. Disponível em: <http://www.schattauer.de/ de/magazine/uebersicht/zeitschriften-a-z/thrombosis-andhaemostasis/contents/archive/issue/348/manuscript/9459.html . Acesso em: 17 maio, 2011. doi: 10.1160/TH07-10-0603.

HEO, S.J. et al. Antioxidant activity of enzymatic extracts from brown seaweeds. Bioresearch Technology, v.96, n.14, p.16131623, 2005. Disponível em: <http://www.sciencedirect.com/ science?_ob=ArticleURL\&_udi=B 6 V2 4-4FN4VS 5$1 \& \_u s e r=10 \&$ \&coverDate $=09 \% 2 \mathrm{~F} 30 \% 2 \mathrm{~F} 2005 \&$ \&alid $=1755437123 \&$ rdoc $=1 \&$ fmt=high\&_orig=search\&_origin=search\&_zone=rslt_lis t_item\&_cdi $=5692 \&$ sort $=r \& \_s t=13 \&$ docanchor $=\&$ view $=c \&$ c $\mathrm{t}=308$ \&_acct $=C 000050221$ \&_version=1\&_urlVersion=0＆_userid=10 $\& m d 5=d 095 a 01$ be $8 \mathrm{ac} 75 \mathrm{~d} 744 \mathrm{~d} 2583 \mathrm{e} 8 \mathrm{da} 905 \mathrm{e} 2 \&$ searchtype $=\mathrm{a}>$. Acesso em: 17 maio, 2011. doi: 10.1016/j.biortech.2004.07.013. 
LI, N. et al. Toxicological evaluation of fucoidan extracted from Laminaria japonica in Wister rats. Food and Chemical Toxicology, v.43, n.3, p.421-426, 2005. Disponível em: <http:/ /www.sciencedirect.com/science?_ob=ArticleURL\&_udi=B6T6P4F3NXSR\&_user $=10 \& \_c o v e r D a t e=03 \% 2 \mathrm{~F} 01 \% 2 \mathrm{~F} 2005 \& \_$alid $=175544141$ $3 \& \_r d o c=13 \& \_f m t=h i g h \& \_o r i g=s e a r c h \& \_o r i g i n=$ search \&_zone $=r$ slt_list_item\&_cdi $=5036 \& \_$_sort $=r \& \_s t=13 \& \_$docanchor $=\&$ view $=c \& \_c t=675 \& \_a c c t=C 000050221 \& \_v e r s i o n=1 \& \_u r l$ Version $=0 \&$ _userid $=10 \& \mathrm{md} 5=\mathrm{f} 40 \mathrm{e} 4 \mathrm{eab} 86 \mathrm{e} 3602 \mathrm{~b} 3 \mathrm{e} 07 \mathrm{aab} 2163252 \mathrm{fb} \&$ searchtype $=\mathrm{a}>$. Acesso em: 17 maio, 2011. doi: 10.1016/j.fct.2004.12.001.

LINS, K.O.A. et al. Antitumor properties of a sulfated polysaccharide from the red seaweed Champia feldmannii (Dias-Pifferer). Journal of Applied Toxicology, v.29, n.1, p.20-26, 2009. Disponível em: <http://onlinelibrary.wiley.com/doi/10.1002/jat.1374/ abstract;jsessionid=E23A54115915B848DE221 ADFD1E5E459.d 03 t02? systemMessage $=$ Wiley+Online+Library+will+be+disrupted+ 21+May+from+10-12+BST+for+monthly+maintenance>. Acesso em: 17 maio, 2011. doi: 10.1002/jat.1374.

MAJERUS, P.W.; TELLOFSEN, D.M. Anticoagulantes, trombolíticos e fármacos antiplaquetários. In: GILMAN, A.G. As bases farmacológicas da terapêutica. Rio de Janeiro: McGraw-Hill, 2005. Seção.11, p.1141-1155.

MASUKO, T. et al. Carbohydrate analysis by a phenol-sulfuric acid method in microplate format. Analytical Biochemistry, v.339, n.1, p.69-72, 2005. Disponível em: <http://www.sciencedirect.com/ science?_ob=ArticleURL\&_udi=B 6 W 9 V-4F473 KN1\&_user=10\&_coverDate=04\%2F01\%2F2005\&_alid=1755443129\&_ rdoc $=1 \& \_f m t=h i g h \& \_o r i g=s e a r c h \& \_o r i g i n=s e a r c h \& \_z o n e=r s l t \_l i s t$ _item\&_cdi $=6692 \& \_s o r t=r \& \_s t=13 \& \_d o c a n c h o r=\& v i e w=c \& \_c t=$ $46 \& \_a c c t=C 000050221 \& \_v e r s i o n=1 \& \_u r l$ Version $=0$ \&_userid $=10 \& \mathrm{md} 5=7$ b6df499c56b2b96eda3104c4a15034b\&searchtype=a>. Acesso em: 17 maio, 2011. doi: 10.1016/j.ab.2004.12.001.

MURANO, E. et al. Investigation of the carrageenans extracted from Solieria filiformis and Agardhiella subulata from Mar Piccolo, Taranto. Marine Chemistry, v.58, n.3-4, p.319325, 1997. Disponível em: <http://www.sciencedirect.com/ science?_ob=ArticleURL\&_udi=B 6VC2-3 T 7 HJ 69W\&_user=10\&_coverDate $=11 \% 2 F 30 \% 2 F 1997 \& \_a l i d=1755442187$ \&_rdoc $=1 \& \_$fmt=high\&_orig=search\&_origin=search\&_zone $=$ rsit_list_item\&_cdi $=5942 \& \_s o r t=r \& \_s t=13 \& \_$docanchor $=\& v i$ ew $=c \& \_c t=18 \& \_a c c t=C 000050221 \& \_v e r s i o n=1 \& \_u r l$ Version $=0 \& \_$ userid=10\&md5=02c8041a36e 036f5ca49c5f63cf3cfa5\&searchtype $=\mathrm{a}>$. Acesso em: 17 maio, 2011. doi: 10.1016/S03044203(97)00058-3.

PEREIRA, M.G. et al. Structure and anticoagulant activity of a sulfated galactan from the red alga, Gelidium crinale. Is there a specific structural requirement for the anticoagulant action? Carbohydrate Research, v.340, n.12, p.20152023, 2005. Disponível em: <http://www.sciencedirect.com/ science?_ob=ArticleURL\&_udi=B 6 TFF-4GMJ $99 \mathrm{~J}-$ $3 \& \_$user $=10$ \&_coverDate $=09 \% 2 \mathrm{~F} 05 \% 2 \mathrm{~F} 2005 \& \_$alid $=1755444911 \& \_$rd $\mathrm{oc}=1 \&$ \&mt=high\&_orig=search\&_origin $=$ search\&_zone=rsit_list_it em\&_cdi $=5225 \& \_s o r t=r \& \_s t=13 \& \_d o c a n c h o r=\& v i e w=c \& \_c t=33 \& \_a c c t$
$=C 000050221 \& \_v e r s i o n=1 \& \_u r \mid$ Version $=0 \& \_u s e r i d=10 \& m d 5=79 \mathrm{bfab} 7072 \mathrm{~b}$ $5015 \mathrm{f} 39 \mathrm{ffd} 4 \mathrm{e} 7 \mathrm{c} 9 \mathrm{f} 6 \mathrm{af} 7 \&$ searchtype $=\mathrm{a}>$. Acesso em: 17 maio, 2011. doi: 10.1016/j.carres.2005.05.018.

REIS, R.P. et al. Potencial para maricultura da carragenófita Hypnea musciformis (Wulfen) J. V. Lamour. (Gigartinales - Rhodophyta) na Ilha da Marambaia, Baía de Sepetiba, RJ, Brasil. Acta Botânica Brasílica, v.20, n.4, p.763-769, 2006. Disponível em: <http:// www.scielo.br/scielo.php? script=sci_abstract\&pid=S0102$33062006000400002 \& \operatorname{lng}=\mathrm{pt} \& \mathrm{nrm}=\mathrm{iso} \& \mathrm{t} \operatorname{lng}=\mathrm{pt}>$. Acesso em: 17 maio, 2011. doi: 10.1590/S0102-33062006000400002.

RODRIGUES, J.A.G. et al. Extração e atividade anticoagulante dos polissacarídeos sulfatados da alga marinha vermelha Halymenia pseudofloresia. Revista Ciência Agronômica, v.40, n.2, p.224-231, 2009. Disponível em: <http:// www.ccarevista.ufc.br/seer/index.php/ccarevista/article/view/ 515/333>. Acesso em: 17 maio, 2011.

RODRIGUES, J.A.G. et al. Isolamento, fracionamento e atividade anticoagulante de iota-carragenanas da Solieria filiformis. Ciência Rural, v.40, n.11, p.2310-2316, 2010. Disponível em: <http:// www.scielo.br/scielo.php? script=sci_abstract $\&$ pid $=$ S0 $103-$ $84782010001100010 \& \operatorname{lng}=\mathrm{pt} \& \mathrm{nrm}=\mathrm{iso} \& \mathrm{t} \operatorname{lng}=\mathrm{pt}>$. Acesso em: 17 maio, 2011. doi: 10.1590/S0103-84782010001100010.

RODRIGUES, J.A.G. et al. An antithrombin-dependent sulfated polysaccharide isolated from the green alga Caulerpa cupressoides has in vivo anti- and prothrombotic effects. Ciência Rural, v.41, n.4, p.634-639, 2011a. Disponível em: <http://www.scielo.br/ scielo.php?script=sci_abstract\&pid=S010384782011000400014\&lng=pt\& $\mathrm{nrm}=\mathrm{iso} \&$ tlng=pt $>$. Acesso em: 03 jun. 2011. doi: 10.1590/ S0103-84782011000400014.

RODRIGUES, J.A.G. et al. Carragenana da epífita Hypnea musciformis obtida do cultivo experimental de Solieria filiformis em Flecheiras, Estado do Ceará, Brasil. Acta Scientiarum. Technology, v.33, n.2, p.137-144, 2011b. Disponível em: <http://periodicos.uem.br/ojs/index.php/ActaSciTechnol/article/ view/9096/9096>. Acesso em: 17 mai. 2011. doi: 10.4025/ actascitechnol.v33i2.9096.

SILVA, F.R.F. et al. Anticoagulant activity, paw edema and pleurisy induced carrageenan: action of major types of commercial carrageenans. Carbohydrate Polymers, v.79, n.1, p.26-33, 2010. Disponível em: <http://www.sciencedirect.com/ science?_ob=ArticleURL\&_udi=B6TFD-4WRM6JD9\&_user $=10 \& \_c o v e r D a t e=01 \% 2 \mathrm{~F} 05 \% 2 \mathrm{~F} 2010 \& \_$alid $=1755452335 \&$ _ $\mathrm{rdoc}=1 \&$ fmt=high\&_orig=search\&_origin=search\&_zone=rslt_list_ $\mathrm{i}$ tem\&_cdi $=5224 \& \_\mathrm{st}=13 \& \_d o c a n c h o r=\& v i e w=c \& \_\mathrm{ct}=3 \& \_\mathrm{acct}=\mathrm{C} 000050221$ \&_version $=1$ \&_urlVersion $=0 \&$ userid $=10 \& \mathrm{md} 5=\mathrm{cb} 58098769 \mathrm{e} 25 \mathrm{~d} 49 \mathrm{c} 73 \mathrm{~b}$ 0afd817ef791\&searchtype =a>. Acesso em: 17 maio, 2011. doi: 10.1016/j.carbpol.2009.07.010.

SIQUEIRA, R.C.L. et al. In vivo anti-inflammatory effect of a sulfated polysaccharide isolated from the marine brown algae Lobophora variegata. Pharmaceutical Biology, v.49, n.2, p.167-174, 2011. Disponível em: <http://informahealthcare.com/ doi/abs/10.3109/13880209.2010.505605>. Acesso em: 17 maio, 2011. doi: $10.3109 / 13880209.2010 .505605$. 